Hochfränkisch und oberdeutsch (Zs. fda. 37, 288). Aus seiner darlegung geht hervor; dass diese grenze im ganzen mit anderen festen und alten grenzen zusammenfällt; somit muss die heutige verteilung in alte zeiten zuruckgehen. Daraus ergibt sich, dass die mittel- und niederdeutschen dichter, die nördlich von dieser linie zu hause sind und die das $l$-suffix verwenden, dies nicht auf grund ihrer heimischen mundart tun; wir erhalten somit einen weiteren bedeutsamen beweis für das bestehen einer mittelbochdeutschen, auf oberdeutschem boden ausgebildeten schriftsprache. Ich hoffe in nicht allzuferner zeit ausfuhrlicher auf diese dinge eingehen zu können.
GIESSEN, 20. nov. 1893.
O. BEHAGHEL.

\title{
ZU BEITR. 18, 243.
}

Ai. pyúkshna- 'uberzug des bogenstabs' stimmt zu gr. $\pi \tau v$ $\sigma \sigma \infty$ nicht bloss im ersten element, sondern darf geradezu als eine bildung aus diesem verbum betrachtet werden, da es zu dessen grundbedeutung 'schiebe darlbber' stimmt. Wir hätten dann neben íthati 'schieben' eine bildung mit $\breve{u}$. Andere wörter auf -sna verzeichnen Lindner, Altind. nominalbildung s. 112. Whitney, Grammatik $\S 1195$.

\section{BASEL.}

J. WACKERNAGEL. 